\title{
Efficient Retail Pricing in Electricity and Natural Gas Markets*
}

\author{
Steven L. Puller ${ }^{\dagger}$ \\ Department of Economics \\ Texas A\&M University and NBER
}

\author{
Jeremy West $\ddagger$ \\ Department of Economics \\ Texas A\&M University
}

January 2013

\section{Abstract}

A long line of research investigates whether the retail prices of electricity and natural gas send proper signals about scarcity in order to induce efficient consumption. Historically, regulated utilities have not designed tariffs that set marginal prices equal to marginal costs. Currently, some jurisdictions are opening the retail sectors to competition via "retail choice." These new regimes replace imperfect regulation with imperfect competition as the process by which retail tariffs are formed. We discuss the challenges in evaluating the efficiency of tariffs and present evidence of how pricing has changed in markets with retail choice.

\section{JEL codes: L11, Q41, Q48}

${ }^{*}$ Forthcoming in The American Economic Review Papers and Proceedings.

We thank Severin Borenstein and Koichiro Ito for useful discussions and Kim Castanon, Jose Castillo, and Robert Manning for research assistance.

${ }^{\dagger}$ Email: puller@econmail.tamu.edu

${ }^{\ddagger}$ Email: jwest@econ.tamu.edu 


\section{Introduction}

Researchers have investigated the efficiency of retail pricing in the electricity and natural gas industries for decades. Historically, the challenge has been to set prices in a manner that ensures a regulated utility covers its investment and production costs while simultaneously providing consumers with optimal incentives to consume. A common theoretical solution is to use a two-part tariff that includes a fixed component along with a marginal usage price set equal to the marginal cost of provision. In practice, tariffs set via a regulatory process often deviate from theoretical prescriptions for optimal two-part tariffs.

Although some jurisdictions continue to follow this regulated utility model, others are opening retail electricity and natural gas sectors to competition via "retail choice." Many areas in the U.S. and UK, for example, allow end-users including residential customers to choose their retail provider. In these jurisdictions, the form of tariff functions by entrant retailers is not an outcome of a regulatory process. Rather, these tariffs arise from the strategic interaction of firms that compete for customers, albeit in markets that are unlikely to be perfectly competitive. Thus, these new retail choice regimes replace imperfect regulation with imperfect competition as the process that creates retail tariffs.

In this article, we discuss the challenges in evaluating the efficiency of tariffs and present evidence that prices continue to diverge from marginal cost after retail choice is introduced.

\section{The Pricing Problem in Retail Electricity and Nat- ural Gas}

A regulated utility's pricing challenge is the well-known natural monopoly pricing problem. Transmission and distribution (T\&D) in the electricity industry have natural monopoly characteristics: high fixed costs make it very inefficient to build redundant sets of longdistance transmission lines or local distribution infrastructure. Similarly, retail distribution

in the natural gas industry is characterized by high fixed costs and low variable costs. To recover these investment costs, the T\&D components must be "priced into" retail charges for electricity and natural gas. 
The electricity industry faces another dimension along which costs need to be incorporated into pricing - the timing of consumption. Although some natural gas can be stored in the distribution system, electricity cannot be efficiently stored on a large scale, which requires balancing production and consumption at every moment in time. Because demand follows pronounced daily patterns, the variable cost of production is often substantially higher during peak as compared to off-peak periods. Retail prices could vary as frequently as every ten minutes to reflect the localized marginal cost of production, but there is currently little take-up of dynamic pricing schemes for residential customers. Joskow and Wolfram (2012) discuss some of the current challenges in dynamically pricing electricity.

Throughout most of the U.S. experience, the distribution sector of the natural gas industry and all sectors of the electricity industry have been regulated utilities. For the natural gas industry, a common theoretical prescription is to use a two-part tariff where the marginal price of the tariff function is set equal to marginal cost.

Because power is not storable in the electricity sector, the efficiency properties of pricing schemes are more nuanced. Joskow and Tirole (2006) provide a detailed theoretical analysis of the efficiency of pricing under both monopoly provision and retail competition. First-best solutions are generally achievable only if retail customers have their consumption metered on a real-time basis and face retail prices reflecting real-time wholesale scarcity. In the absence of real-time pricing, inefficiencies arise. Customers who pay a variable usage price that does not adjust to match system grid conditions will over-consume during peak periods and under-consume off-peak. Moreover, Joskow and Tirole show that retail competition only exacerbates this inefficiency.

Finally, jurisdictions with retail choice face another source of inefficiency in imperfect competition. Studies of residential markets with retail choice suggest that there is considerable consumer inertia to remain with the incumbent (e.g. Giulietti et al., 2005; Hortaçsu et al., 2012). 


\section{Challenges in Defining Benchmarks for Retail En- ergy Price Efficiency}

Despite fairly clear normative theoretical prescriptions, constructing a benchmark for optimal pricing is not straightforward in practice. We discuss two important complications in evaluating whether tariffs provide optimal consumption signals.

First, utilities lack adequate incentives to fully incorporate external costs into their marginal price. Production and consumption in the natural gas and electricity industries generate emission costs, and these are often not fully internalized.

Second, utility customers may not respond to the marginal price of gas or electricity in the manner implied by standard theory. Electric and gas utilities typically charge non-linear tariffs that include a fixed "customer charge" along with variable usage charges, which often take the form of increasing block tariffs.

Suppose that customers respond to larger utility bills by consuming less energy, ceteris paribus. This observed behavior is consistent with consumers responding to either the marginal price (i.e. the slope of the non-linear tariff) or to their average price (e.g. the average $\phi / \mathrm{kWh}$ that is reported on many bills). Either behavioral response is possible depending on consumer knowledge of the tariff function and the type of information that is saliently reported on bills. Utility bills often do a poor job of clearly displaying the marginal price of each additional unit of energy. It is common for utility bills to display some breakdown of total expenditures, but bills (that we observe) often do not saliently display the marginal price schedule. Casual empiricism suggests that utility customers are better informed about their total monthly expenditures on gas/electricity rather than the marginal price; contrast this with drivers who are likely better informed about the (marginal) price per gallon than their total monthly expenditures on gasoline.

In general, average prices may be above or below marginal prices depending on the size of the fixed charge and the extent to which increasing block tariffs are utilized. Thus, consumers responding to the average price rather than the marginal price may either over or under-consume relative to the theoretically optimal level of consumption. Ito (2012) tests how consumers respond to nonlinear tariffs by using a spatial discontinuity research design, which exploits variation across two contiguous electric utilities that use different 
tariff functions. His results indicate that consumers respond to changes in average prices rather than to marginal prices. This line of research suggests that if academics are to make policy recommendations based upon "getting the marginal price right," then we also should advocate for bill design that saliently displays that price signal.

Because it is unclear to which price signals consumers respond, our analysis below compares the marginal cost of provision to both marginal and average prices.

\section{Retail Competition and the Efficiency of Pricing in the U.S.}

During the last decade, the number of retail customers purchasing energy services from a firm other than a regulated utility increased substantially. Several states opened retail markets in which new entrants procure wholesale power and gas and market it to commercial, industrial, and residential customers. In the analysis below, we consider one of these industry sectors - residential electricity - and study how tariffs change when retail choice is introduced. Although the complications discussed in section 3 preclude fully evaluating the efficiency of observed tariffs, we assess whether features of regulated tariffs that are thought to generate inefficiency persist under retail competition.

In particular, we investigate whether monthly tariffs to residential customers send accurate signals about the marginal cost of power. It is important to keep in mind that this is testing for second-best pricing. Dynamic prices are necessary to achieve the first-best solution, but it appears unlikely in the near-term that many residential customers will face real-time tariffs. Therefore, it is valuable to investigate how closely monthly tariffs reflect the marginal cost of power (averaged over the hours of the month) and generate proper (second-best) consumption signals. We discuss initial evidence using data from Texas, the state that ranks highest in electricity consumption and has a high rate of participation in retail electricity choice programs.

It is a priori ambiguous whether transitioning to competition improves the efficiency of pricing - tariffs with the inefficiencies generated by the regulatory process are replaced by those arising from imperfectly competitive retail markets. 
The regulatory process is known to generate multi-part tariffs in which the marginal price diverges from marginal cost. Fixed distribution costs are priced into the usage component of tariffs rather than solely into the fixed customer charge. For the case of natural gas, Davis and Muehlegger (2010) find that residential and commercial customers face retail prices that are more than $40 \%$ above marginal cost. Additionally, state public utility commissions often establish increasing block rates so that higher usage consumers pay a higher price on the margin. These increasing block tariffs are poorly conceived from an efficiency perspective. One motivation for higher marginal prices is to encourage conservation; however, the marginal social cost of one more unit of consumption is not any higher for an individual consumer's 499th kilowatt-hour than the consumer's 500th kWh. Equity concerns often serve as another motivation, but Borenstein and Davis (2010) find only a weak correlation of natural gas consumption with income.

Under a retail choice regime, other factors determine tariff design. Joskow and Tirole show that a perfectly competitive retail market would not involve increasing block tariffs: customers would be charged the same marginal price for all units of consumption. However, in an imperfectly competitive market in which consumers exhibit inertial preference for the incumbent, tariffs set by the incumbent firm - perhaps via regulatory mandate - will impact the tariff functions chosen by competitive retailers.

\section{Empirical Analysis of Tariffs Under Retail Competi- tion}

We present evidence on how electricity tariffs change when retail competition was introduced in Texas in January 2002. Areas of the state served by investor-owned utilities were required to allow entry of competitive retailers. Incumbent retailers charged a regulated tariff called the price-to-beat, and entrants were allowed to choose any tariff functions. Areas served by municipal utilities opted out of retail choice.

We examine tariffs of two regulated incumbents, competitive entrants into the deregulated markets, and a "control" composed of two large municipal utilities that remained regulated throughout the entire time period. We view the control municipal utilities not as counterfactuals for the incumbents but rather as comparison utilities that face similar demand and cost shocks. 
Our analysis investigates two characteristics of tariff functions: (1) do marginal and/or average prices reflect marginal costs, and (2) do firms use increasing/decreasing block or single-block tariffs?

\subsection{Data}

We collected data on the residential tariff functions for the two largest territories that were opened to retail competition and the two largest municipal utilities that remained regulated for a period spanning the introduction of retail choice in 2002. Specifically, we include the monthly residential tariffs from January 1997 to July 2006 for TXU (which we refer to as "Dallas area") and Reliant ("Houston area") to analyze areas opened to competition. We also use tariffs for City Public Service of San Antonio and Austin Energy, which were regulated for the entire period. Data on regulated tariffs are gathered from each utility. Tariffs from the retail choice regime were provided by the Public Utility Commission of Texas.

The marginal cost of delivering an additional $\mathrm{kWh}$ of retail power is estimated with the average monthly wholesale price of power in Texas. We calculate the load-weighted average monthly wholesale price of electricity in Texas using daily wholesale prices from Megawatt Daily for the region of ERCOT that matches each territory.

The information on tariffs and wholesale prices allow us to measure the monthly difference between the actual marginal retail price and realized marginal energy costs for any usage level in each territory. In order to determine representative usage levels, we use a sample of nineteen thousand individual customers' monthly meter-reads to create a distribution of consumption levels.

\subsection{Do Tariffs Send Correct Price Signals?}

Figure 1 displays the differences between marginal price and marginal costs before and after retail deregulation in 2002. In order to create these figures, we calculate markups evaluated at each usage level from the distribution of consumption for each provider-month. From these, we compute the simple average markup.

Panel (a) shows markups in the Houston area. The "Control utilities" series is the (territory size weighted) average retail markup across the two areas that never allowed retail choice; the average markup was $5.10 \notin / \mathrm{kWh}$ prior to 2002 and $4.11 \mathrm{c} / \mathrm{kWh}$ after 2002. 
The other three series are informative about changes associated with retail choice. The "Treated incumbent" was required to charge the regulated price-to-beat, so the incumbent's pricing does not represent the outcome of retail choice, but rather is a driver of market forces under retail choice. For the Houston incumbent, the average margin was $6.464 / \mathrm{kWh}$ prior to 2002 and $6.50 \mathrm{c} / \mathrm{kWh}$ after 2002. The series "Large entrant" shows that a major new entrant priced only slightly below the price-to-beat $(5.67 \mathrm{c} / \mathrm{kWh}$ average markup). The series "Low-cost entrant" plots the weighted-average retail price margin $(3.87 \mathrm{\phi} / \mathrm{kWh}$ on average) for the set of entrant firms yielding the lowest total bill for each consumption level. Panel (b) shows markups in the Dallas area, and we find markups that are somewhat smaller than in Houston but still around $5 \leftarrow / \mathrm{kWh}$ on average.

Because consumers might respond to average prices rather than marginal prices, we separately calculate differences between average price and marginal cost. Figures depicting the resulting margins (available in the Online Appendix) exhibit similar patterns, with differences that are slightly larger than those shown in Figure 1.

This analysis shows that marginal and average retail prices diverge from marginal cost both before and after retail deregulation. If consumers respond to either of these two features of tariffs, then there will be a quantity distortion relative to price signals that reflect the wholesale cost of power. In this article, we do not attempt to assess the welfare consequences of this pricing; such a calculation requires information on external costs and the demand function. However, our analysis does suggest that a quantity distortion relative to the marginal cost of production continues to persist after retail competition was introduced in Texas.

\subsection{Do Tariffs Utilize Single Block Pricing?}

We also explore the extent to which increasing block tariffs continue to be used under a retail choice regime. As we discuss above, tiered pricing schemes are inconsistent with marginal cost pricing (either social or private), and often are motivated by distributional or conservation goals. Moreover, retail competition should undermine the ability to charge multi-block tariffs.

However, evidence from the first years of the Texas retail market suggests that tiered pricing continues under retail choice. For each month and provider, we compute the marginal 
price across a distribution of usage levels and then calculate the standard deviation of these marginal prices. If a provider levies only a single block tariff for a given month, then all customers pay the same marginal price and the standard deviation is zero. However, if the provider uses an increasing (or decreasing) block tariff, then customers pay different marginal prices and the standard deviation of these prices will be positive. The magnitude depends upon the size of price difference between the tiers and the frequency with which customers consume on the different tiers.

Figure 2 plots the monthly standard deviation for several providers before and after retail choice is introduced in 2002. In Panel (a) for the Houston area, the series for the "Treated incumbent" reflects that fact that the regulated price-to-beat included increasing block pricing, and this yields similar levels of variation in marginal prices as prior to deregulation. The "Large entrant" series indicates that this retailer entered the market with single block tariffs for the first year but then switched to an increasing block tariff yielding similar levels of variation in marginal prices as the price-to-beat. The series "Low-cost entrant" exhibits slightly less dispersion, but nevertheless reflects using tiered pricing that generates substantial dispersion in effective marginal prices.

In Panel (b) for the Dallas area, there is generally less variation in marginal prices than in Houston, especially in the summer when the Incumbent and Large entrant (but not the Low-cost entrant) utilize single block tariffs. However, all firms use multi-block tariffs in the winter that generate dispersion in marginal price.

Finally, let us comment on external validity. The changes in tariffs from introducing retail competition can vary substantially across jurisdictions depending on how the transition to competition is regulated. States have taken different approaches to set the rate charged by the incumbent firm, which in a market with consumer inertia can have a large impact on pricing by new entrant retailers. In Texas, the public utility commission regulated the incumbent's rate at a level that was thought to be above competitive levels with the goal of encouraging entry by other retailers. States that follow different transition strategies could experience different changes in the shape, level, and distribution of tariff functions. 


\section{Discussion}

The introduction of retail competition in electricity and natural gas markets is generating important new areas of research on retail pricing. Economists have focused attention on the marginal price as the relevant signal of scarcity. The extent to which consumers respond to this signal depends upon the saliency of tariff information. In new retail markets, bills are designed by firms who compete for customers rather than by regulatory commissions. In settings with retail choice, it will be interesting to observe which types of information on price and usage are saliently displayed on bills.

Finally, research should continue to explore the competitiveness of these new retail markets and the inertia surrounding incumbent firms. Ultimately, the welfare implications for retail choice will depend upon the competitiveness of the retail markets, the nature of the tariff functions, and the information about those tariff functions that is saliently conveyed to customers.

\section{References}

Borenstein, S. and Davis, L. W. (2010). The equity and efficiency of two-part tariffs in U.S. natural gas markets. Working paper 16653, National Bureau of Economic Research.

Davis, L. W. and Muehlegger, E. (2010). Do Americans consume too little natural gas? An empirical test of marginal cost pricing. The RAND Journal of Economics, 41(4):791-810.

Giulietti, M., Price, C. W., and Waterson, M. (2005). Consumer choice and competition policy: A study of UK energy markets. The Economic Journal, 115:949-968.

Hortaçsu, A., Madanizadeh, S. A., and Puller, S. L. (2012). Power to choose? an analysis of choice frictions in the residential electricity market. Working paper.

Ito, K. (2012). Do consumers respond to marginal or average price? Evidence from nonlinear electricity pricing. Working paper.

Joskow, P. L. and Tirole, J. (2006). Retail electricity competition. The RAND Journal of Economics, 37(4):799-815.

Joskow, P. L. and Wolfram, C. D. (2012). Dynamic pricing of electricity. American Economic Review: Papers and Proceedings, 102(3):381-385. 


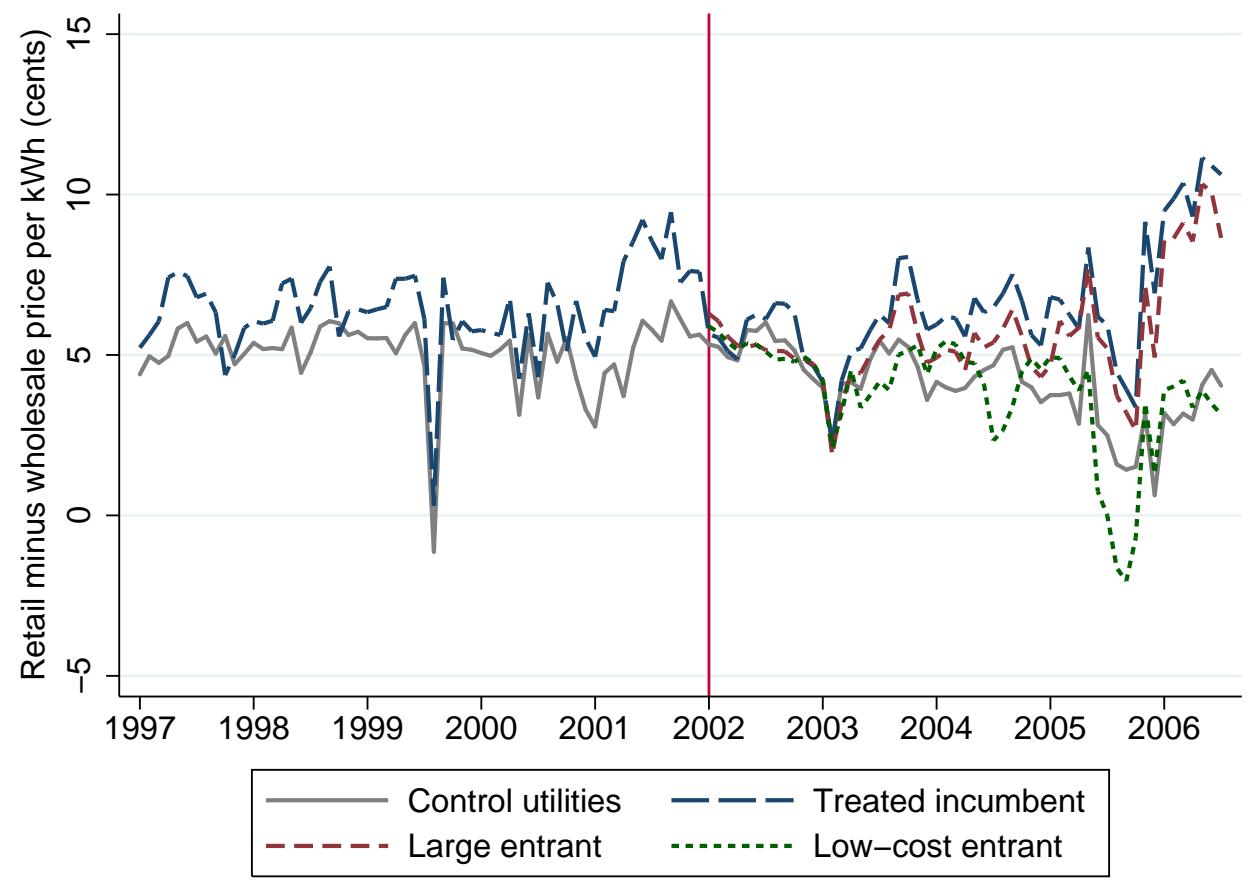

(a) Houston area

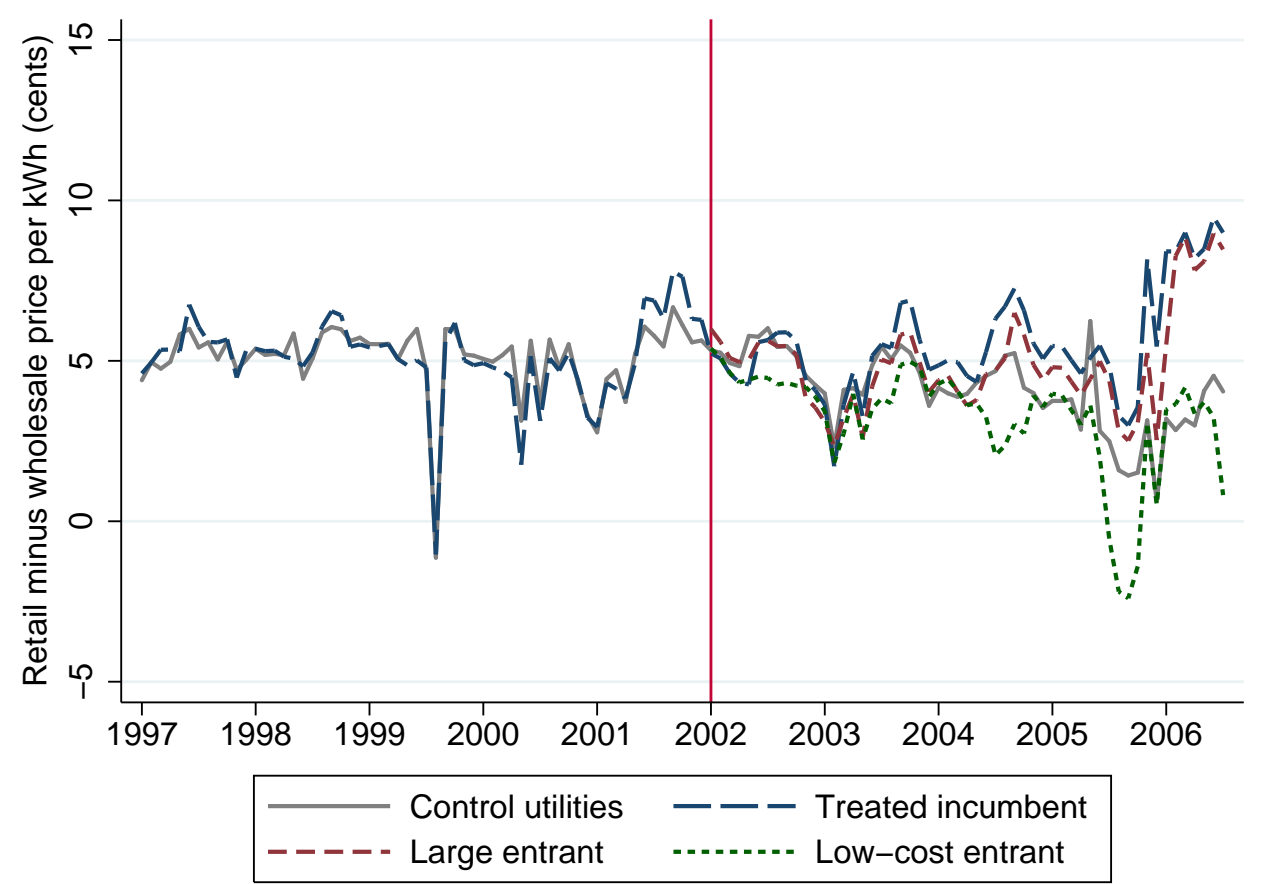

(b) Dallas area

Figure 1: Retail marginal price minus marginal cost: pre- and post-deregulation 


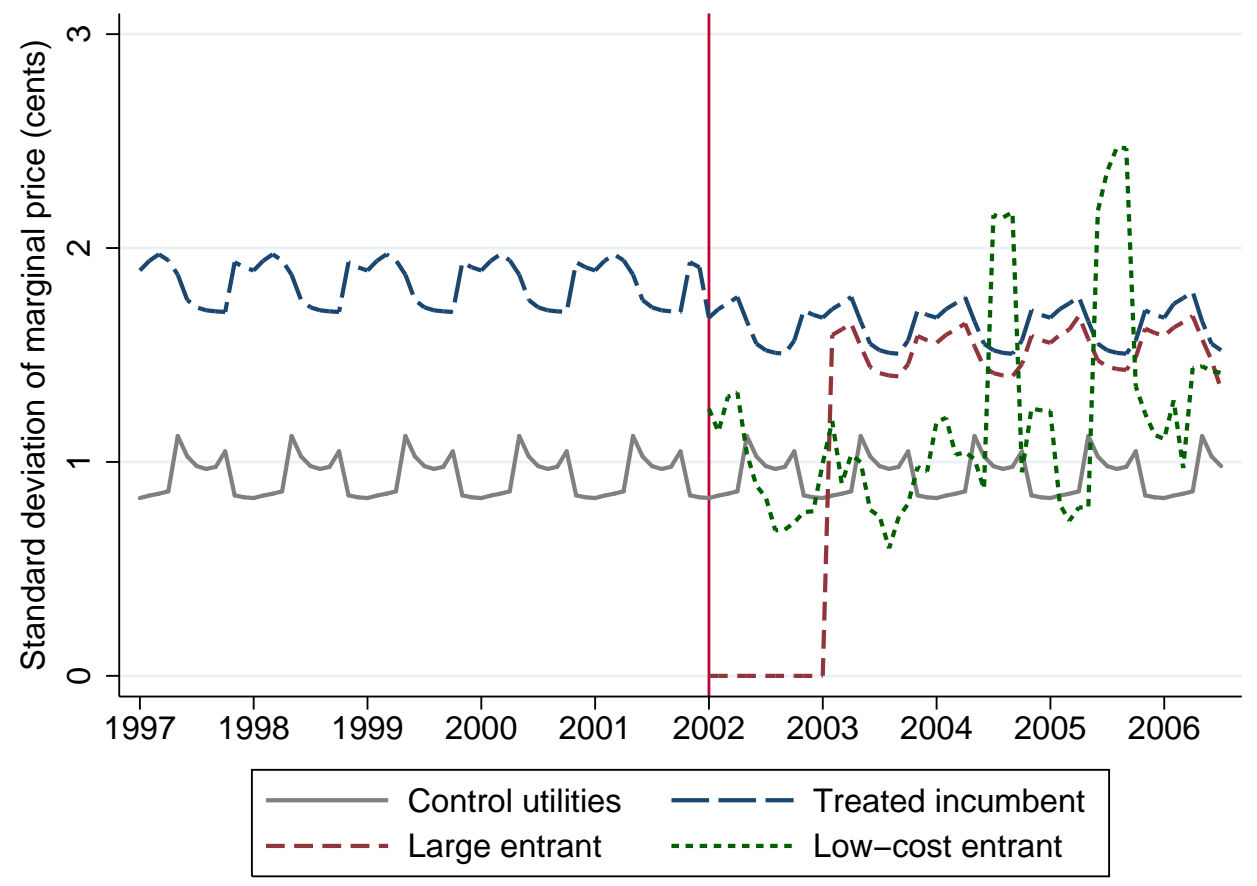

(a) Houston area

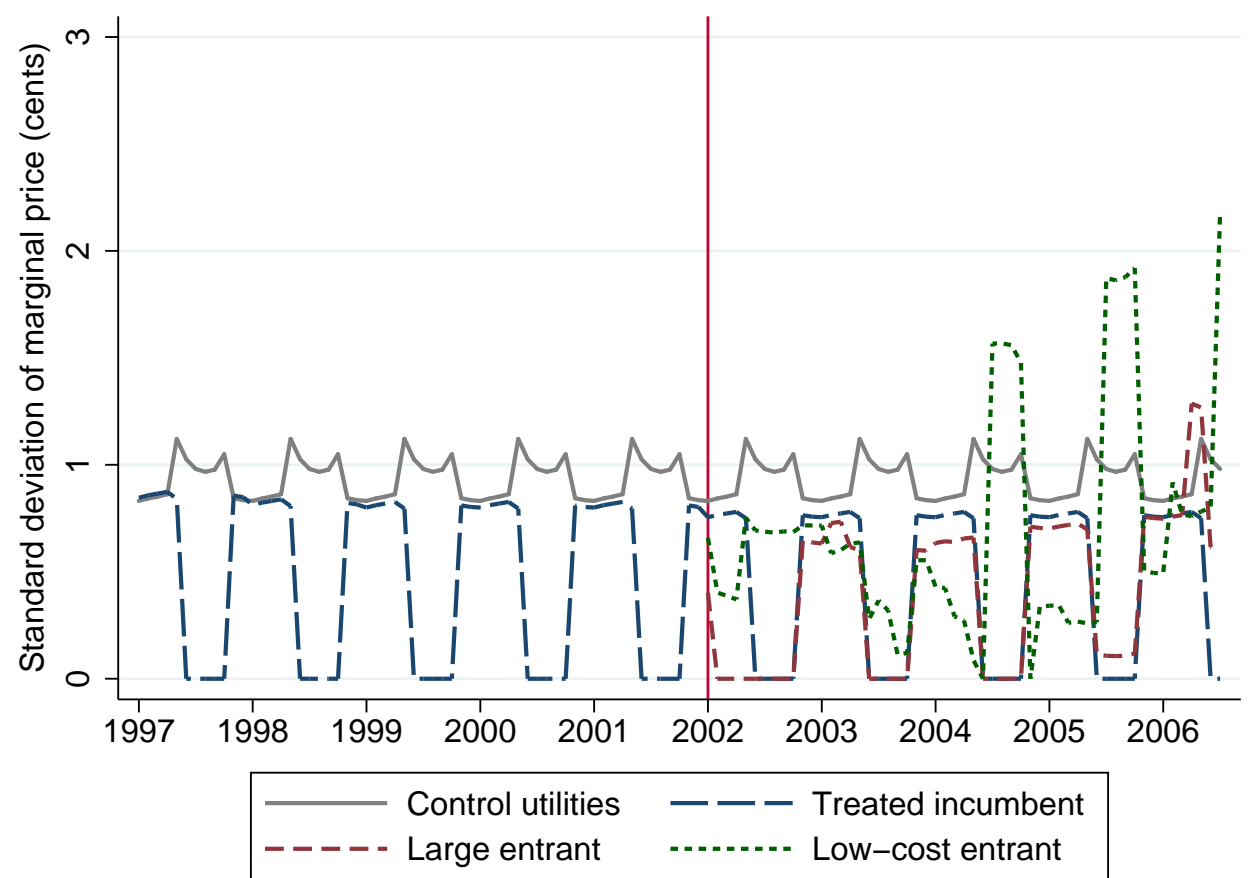

(b) Dallas area

Figure 2: Standard deviation of marginal price across consumers: pre- and post-deregulation 